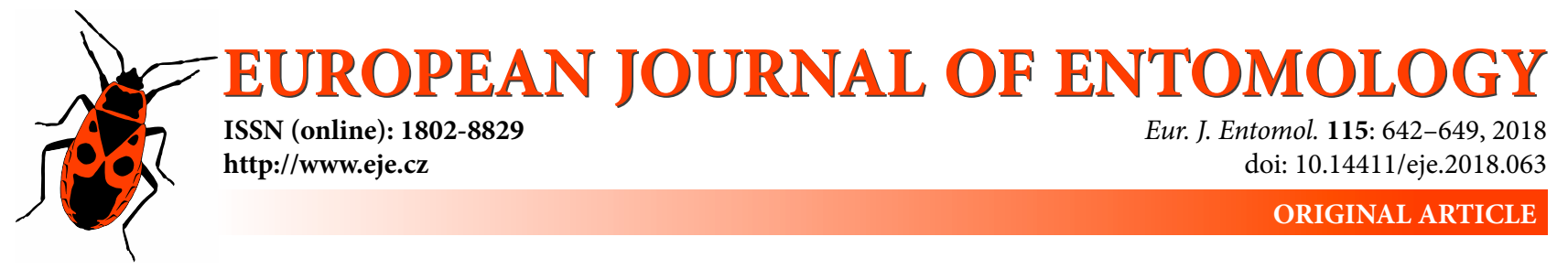

\title{
Density-invariant dispersion indices and fixed precision sequential sampling plans for the peach twig borer Anarsia lineatella (Lepidoptera: Gelechiidae)
}

\author{
Petros DAMOS $^{1,2}$ \\ ${ }^{1}$ Pharmacy Department, University General Infectious Diseases Hospital of Thessaloniki AHEPA, Thessaloniki, Greece; \\ e-mail: petrosdamos@gmail.com \\ ${ }^{2}$ Laboratory of Applied Zoology and Parasitology, Department of Crop Production (Field Crops and Ecology, Horticulture and \\ Viticulture and Plant Protection), Faculty of Agriculture, Forestry and Natural Environment, Aristotle University of Thessaloniki, \\ University Campus, Thessaloniki, Greece; e-mail: damos@agro.auth.gr
}

Key words. Lepidoptera, Gelechiidae, Anarsia lineatella, sampling, spatial dispersion, integrated pest management, moth, peach production

\begin{abstract}
Estimating the spatial dispersion of pest arthropods is crucial for the development of reliable sampling programs and one of the main components of integrated pest management. The natural spatial distribution of a population of a species may be random, uniform, or aggregated and can be so classified based on calculation of variance to mean relations and related dispersion indices. In this work some classical density-invariant dispersion indices and related regression models are used for the first time to quantify the spatial dispersion of an important peach pest Anarsia lineatella Zeller (Lepidoptera: Gelechiidae) and construct fixed precision sequential sampling schemes. Taylor's power law, Iwao's patchiness regression and Nachman's model were used to analyse the damage to peaches caused by $A$. lineatella. All three regression models fit the data well, although the results indicate that Iwao's patchiness model provides a better description of the relationship between variance and mean density. Taylor's $b$ and Iwao's $b$ regression indices were both significantly smaller than 1 , indicating that the distribution of individuals was uniform rather than random or aggregated. According to Green's and Kuno's models, the minimum sample size at the precision level of 0.2 varies from 3 samples, when total population density is more than 3 larvae/sample, to 10 samples, when population density is between 1 and 2 larvae/sample. Kuno's fixed sampling plan indicates that a small number of samples (i.e., 3-10 branches with fruit) is sufficient to estimate the mean population density of $A$. lineatella larvae with a precision of 0.2 . The Resampling for validation of sampling plans (RVSP) method confirmed that the average level of precision of the fixed sequential plans matched the desired precision in most cases. The sampling plan presented here provides a level understanding of $A$. lineatella spatial ecology suitable for pest management decisions.
\end{abstract}

\section{INTRODUCTION}

Insect sampling is a basic component in the decision making process in integrated pest management (IPM) and the development of cost-efficient sampling plans has the potential to increase the adoption of IPM systems by growers and minimize insecticide use. Nevertheless, a prerequisite for developing a sound sampling plan is understanding the spatial distribution of insect populations on crops (Binns \& Nyrop, 1992).

The spatial distribution of a population reflects its demographic and behavioural responses to environmental drivers including, food conditions, predation risk and other habitat factors (Tscharntke et al., 2002; Vinatier et al., 2011). Three basic types of spatial distribution of individuals are recognized: uniform (or regular), random and aggregated (or clumped) (Young \& Young, 1998). Intense competition among individuals for resources such as nu- trients or moisture may maximize the distance between individuals and result in a uniform distribution. Random distribution generally occurs when resources and environmental conditions are homogenous and not limited within a habitat. Patchy resources, finally, may underlie an aggregated distribution, which is most common in natural environments (Heard \& Remer, 1997), and some agrosystems (Ifoulis \& Savopoulou-Soultani, 2006; Hahn et al., 2017).

Southwood (1978) summarised the common methods and related estimates used to describe the spatial arrangement of arthropod pests. Most widespread methods include those based on mean-variance relationships of insect number per sampling unit through time, which provide a fixed year to year relationship based on the observed sampling mean (Taylor, 1961, 1984; Iwao, 1968, 1975; Kuno, 1969, 1991). Other common estimates are based on the correlation between the sample mean and the variance of sam- 
pling units not infested by a pest population (Nachman, 1981, 1984). In this case, the presence or absence of insects serves as a basis for estimating the mean population that significantly reduces sampling cost (Bisseleua et al., 2011). Sequential sampling with a fixed precision has the advantage of considerably reducing the time and cost of estimating insect density in contrast to conventional sampling, where the sample size is fixed in advance (Hutchison, 1994). Thus, in some cases only half the number of observations is required compared to classical sampling (Mace, 1974).

The peach twig borer, Anarsia lineatella Zeller (Lepidoptera: Gelechiidae), causes serious problems in more than 44 countries that cultivate peaches (Sorenson \& Gunnell, 1955; EPPO Global Database, 2018) and is one of the major economic pests of stone fruits worldwide (Balachowsky, 1966; Damos \& Savopoulou-Soultani, 2010). Moreover, among the species that attack stone fruits, $A$. lineatella is the most serious pest and is therefore considered a key pest requiring the establishment and usage of a an effective control strategy in terms of integrated pest management (IPM). A sound IPM strategy requires the development of decision tools such as sampling programs for determining the action to be taken (i.e., pesticide treatments). Such decision tools are, however, not defined for most peach pests including $A$. lineatella.

The purpose of this work is first to develop density-invariant dispersion indices in order to provide information on the spatial distribution of $A$. lineatella larvae in a fruit orchard. Then, based on the information derived from the density-invariant dispersion indices, this paper develops and validates sequential sampling plans at fixed levels of precision to provide peach growers, plant protection advisors and researchers a cost-effective sampling method for the peach twig borer. Compared with fixed-sample size sampling, the motivation for developing fixed-precision sequential sampling plans for different levels of precision, is that it can result in a 35 to $50 \%$ reduction in sampling effort (Binns, 1994).

\section{MATERIAL AND METHODS}

\subsection{Fruit orchards}

Fieldwork was conducted during three successive growth seasons (2005-2007) in four nearby organic fruit orchards of the al.m.me ${ }^{\circledR}$ cooperative (Kouloura Imathias) located in Northern Greece $\left(40.539904^{\circ} \mathrm{N}, 22.310345^{\circ} \mathrm{E}\right)$. Each peach orchard, used as an experimental block, was shaped like a parallelogram and separated from other orchards by $10-20 \mathrm{~m}$ wide cultivated areas. Each block consisted of about 40 peach trees (industrial candy variety Loadel) planted in a regular rectangular $5 \times 5 \mathrm{~m}$ grid with 10 rows and 10 columns. The tree height was ca. $2.5-3.5 \mathrm{~m}$, and the trees were ca. $10+$ years old. No insecticides were applied to these orchards.

\subsection{Data acquisition}

A 2-year branch, ca 1-2 $\mathrm{m}$ above the ground, where most of the fruit occurs, was used as the sampling unit. To have a representative grid of samples in each experimental block data was collected from the second tree in the second row in each experimental block. In total 192 samples were collected in this study, and all the fruit inspected (range: $10 \pm 2$ fruit). All the fruit on each branch were inspected for the presence of larvae regardless of instar. The total number of peaches and of damaged peaches was recorded for each of the branches sampled. Four branches per block per day were examined for 12 successive days (2 weeks). Thus, for each block there were 48 datasets that were used to estimate the mean and variance for each block, yielding a total of 12 replicates.

Accumulated degree-days were used as a criterion to ensure that the counts made in successive years were done at the same time in terms of the development of the pest. Temperature data were collected using a HOBO data-logging unit (Onset Computer Corporation $($ ). Degree-days (DD) were accumulated from March 1st and calculated assuming a linear response and a minimum base threshold for $A$. lineatella of $11.4^{\circ} \mathrm{C}$. Data were collected daily for ca. 2 weeks, as previously described, before harvest and after the accumulation of $850-950 \mathrm{DD}$, a period which is 1 to 2 weeks after the peak of the second flight of adults (Damos \& Savopoulou-Soultani, 2010). In this particular period, fruit changes colour, damage is easily visible and larvae have not yet left the fruit in order to pupate. In addition, there was no sampling during the period of the first flight (overwintering generation) because the fruit is then immature, hard and very small and larvae prefer to feed on the terminal shoots (indicated by shoot flagging).

\subsection{Statistical analyses of density-invariant dispersion indices}

Density-invariant indices of dispersion usually overcome the limitation of sampling scale since in most cases the size of the sample unit usually has little effect on the exponent of Taylor Power law, which is scale invariant (Taylor, 1984; Jørgensen, 1997). Three different models and related parameter indices were chosen in order to obtain a consensus on the spatial dispersion of the larvae: (i) Taylor's power law, (ii) Iwao's patchiness regression and (iii) Nachman's model. All indices were estimated for block sizes with a constant sample size as previously described.

\section{(i) Taylor's power law}

Taylor's power law states that the variance in larval population size $\left(S^{2}\right)$ relates to its mean density $(m)$ as:

$$
S^{2}=\alpha m^{b} \quad \text { (1a), }
$$

which translates into a linear relationship on a log-log scale:

$$
\log S^{2}=\log \alpha+b \log m \quad(1 \mathrm{~b})
$$

in which the index of aggregation $b$ is species specific and $\alpha$ is considered as a sampling factor (Taylor et al., 1978). Index of aggregation indicates a uniform, random, or aggregated dispersion if $b<1, b=1$, and $b>1$, respectively.

\section{(ii) Iwao's patchiness regression}

Iwao's patchiness regression is defined as:

$$
m^{*}=\alpha+b m
$$

where $m^{*}=m+\left(\frac{S^{2}}{m-1}\right)$ is the mean crowding index (Lloyd, $1967)$ and $S^{2}$ and $m$ are the variance and mean of the population as above. The intercept $\alpha$ is the basic index of dispersion and indicates a uniform, random or aggregated dispersion if $\alpha<1, \alpha=$ 1 , and $\alpha<1$, respectively. The slope $b$ is the density coefficient that may be interpreted in the same manner as parameter $b$ in Taylor's power law (Bisseleua et al., 2011).

\section{(iii) Nachman Model}

The Nachman (1981) occupancy-abundance model is included for comparison because it has been traditionally used in agricultural entomology to estimate pest density $m$ from the probability 
$p$ of finding no individuals at a given site (Kuno, 1969; Perry, 1973; Nachman, 1984; Ekbon, 1987; Hepworth \& McFarlane, 1992):

$$
p=\exp \left(-\alpha m^{b}\right)
$$

where $\alpha$ is the scale parameter and $b$ is the dispersion parameter. The distribution is random if $\alpha=b=1$, with $\alpha$ and $b \neq 1$ representing a departure from the Poisson distribution (He \& Gaston, 2000). To estimate the parameters, it is convenient to log-transform equation (3a) twice and regress $m$ on $p$ as follows (Nyrop et al., 1989; Nyrop \& Binns, 1991; Bisseleua et al., 2011):

$$
\ln (m)=A+B \ln (-\ln (p))
$$

In the context of this paper, $p$ is the proportion of fruit within a sampling unit with no damage and $A$ and $B$ are the regression parameters of the linearized model (eq. $3 b$ ), which are not equivalent to $\alpha$ and $b$ of the exponential Nachman model (eq. 3a).

\subsection{Goodness of fit of the spatial models}

Goodness of fit of the models (1a), (2) and (3b) were assessed using the coefficient of determination (Young \& Young, 1998). The significance of the intercepts and slopes of the fitted regressions were tested using a one sample $t$-test with a probability level of $p=0.05$ (Draper \& Smith, 1998).

\subsection{Minimum number of samples and plans for fixed precision sequential sampling}

The minimum number of samples necessary for estimating the mean at a given precision is determined by solving Green's model (Green, 1970):

$$
n=\frac{a m^{b-2}}{D^{2}}
$$

where $n$ is the number of samples, $D$ the specific precision level and $a$ and $b$ are coefficients obtained from model (1). The minimum sample size according to Kuno's model uses the parameters of Iwao's patchiness regression (2) based on Lloyd's mean crowding index $m^{*}$ as follows (Naranjo \& Hutchison, 1997):

$$
n=\frac{(a+1) / m^{*}+(b-1)}{D^{2}}
$$

In fixed precision sequential sampling continues until a sample path crosses a predetermined stop line of a constant precision level at which point sampling stops (Bins \& Nyrop, 1992). The two most common precision levels developed by Green (1970) and Kuno (1969) were used to quantify the plan for fixed precision level sampling. The fixed precision sequential sampling models using Green's (1970) method calculate the sampling stop lines, used as thresholds, from Taylor's power law model as:

$$
T_{n} \geqslant\left(\frac{a n^{1-b}}{D^{2}}\right)^{1 /(2-b)}
$$

where $T_{n}$ is the critical cumulative count over $n$ samples (number of larvae or damaged fruit), $a$ and $b$ are the estimated parameters in model (1a), and $D$ is the desired level of precision (Serra et al., 2013).

Kuno's (1969) fixed-precision sampling algorithm uses the parameters of Iwao's patchiness model (2) based on Lloyd's mean crowding index $m *$. The sequential sampling model identifies the critical cumulative count $T_{n}$ over $n$ samples as:

$$
T_{n} \geqslant(\alpha+1) /\left(D^{2}-\frac{b-1}{n}\right)(7)
$$

where $\alpha$ and $b$ are those estimated in model (2) and $D$ is the desired level of precision. In order to ensure that $T_{n}$ remains positive in Kuno's plan $n>(b-1) / D^{2}$ (Naranjo \& Hutchison, 1997). In population dynamics studies, a precision level of 0.10 is usually suggested (Southwood, 1978), while for decision making in pest management a precision level of 0.20 or 0.25 is preferred (Serra et al., 2013). In the current survey, three precision levels $D=0.10$, 0.15 or 0.20 were chosen to develop plans for sampling that cover most circumstances.

\subsection{Validation of the plans for the fixed sequential resampling}

The method developed by Naranjo \& Hutchinson (1997) for validating sampling plans (RVSP) was used to verify the performance of the fixed sequential plans. Because this validation depends on the use of separate data sets, 16 independent observations were used for this purpose and were excluded when computing the regression parameters of Taylor's power law and Iwao's patchiness. These counts consisted of data accrued from samples from the same experimental blocks but were selected randomly and not used in estimating the parameter values of models (1a), (2) and (3b). Moreover, because the data set used for validation was relatively small, random resampling with replacement was implemented (Naranjo \& Hutchison, 1997). A minimal number of five samples was used for all the simulations along with the fixed precision levels of $0.10,015$ or 0.20 . Resampling was run 500 times for each data set, which is satisfactory in most cases (Naranjo \& Hutchison, 1997) in order to calculate the average, minimum and maximum precision levels, and sample sizes (Serra et al., 2013). Resampling was done using the RVSP V. 2 excel add-on freely available from the United States Department of Agriculture (Naranjo \& Hutchinson, 2016).

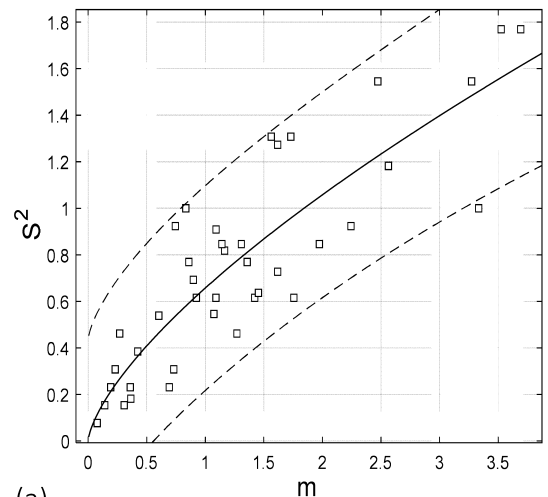

(a)

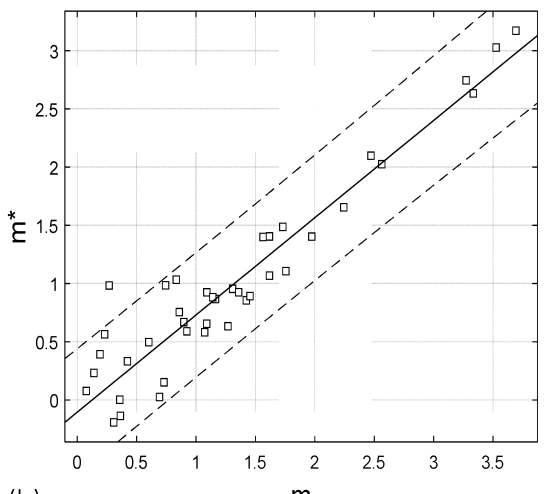

(b)

$\mathrm{m}$

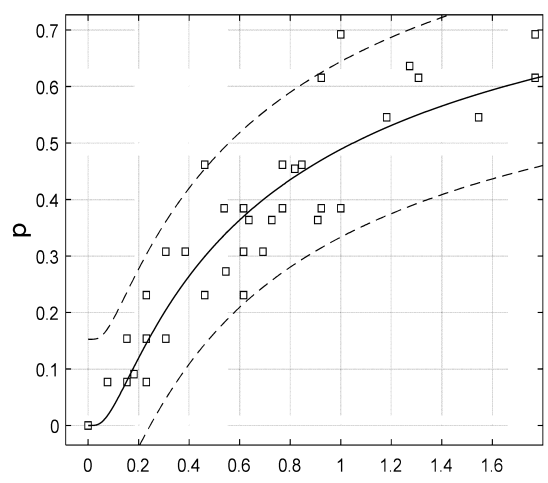

(c)

Fig. 1. Fitted variance to mean (a, b) and probability-of-occupancy to mean (c) relationships for $A$. lineatella larvae based on (a) Taylor's (1a), (b) Iwao's (2) and (c) Nachman's models (3b). Points = individual observations; solid line = model prediction; dashed lines = 95\% Cl. 


\section{RESULTS}

\subsection{Variance-to-mean relationships}

Variance in population size and probability of occupancy increased with mean population size (Fig. 1). Taylor's power law confirmed a significant $(p<0.001)$ and positive relationship between variance $\left(S^{2}\right)$ and mean density $(m)$ (Fig. 1a). The overall regression statistics were significant $(\mathrm{p}<0.001)$ (Table 1). In addition, the index of aggregation $b$ was significantly smaller than $1(\mathrm{p}<0.001)$, thus confirming that the distribution of larvae is uniform rather than random or aggregated.

Fig. $1 \mathrm{~b}$ shows the relationships between the Lloyd mean crowding index and mean density of $A$. lineatella larvae in peaches per sample based on Iwao's regression model $(\mathrm{n}=$ 48). The index of basic contagion, or intercept $\alpha$, was negative for larvae according to Iwao's patchiness regression ( $p$ $<0.001$ ) (Table 1 ). The density contagiousness coefficient estimate, $b$, was significantly larger than zero $(\mathrm{p}<0.001)$ but lower than unity, hinting once again that the distribution of the larvae may be characterized as uniform.

Nachman's model provided a good fit $(p<0.05)$ to the relationship between the percentage of samples that were not attacked by $A$. lineatella larvae $(p)$ and the mean density $m$ of $A$. linetella (Fig. 1c). The nonlinear regression procedure yielded parameter values that were quite similar to those predicted by Taylor's power law model (Table 1). Using these parameters, one can assess the mean density from the fraction of samples (branches with fruit) with or without $A$. lineatella larvae. The coefficient of determination $\left(\mathrm{R}^{2}\right)$ between Taylor's and Iwao's model and the overall results thus indicated a uniform dispersion of larvae.

\subsection{Minimum sampling}

Minimum sample sizes (MSS) decreased with A. lineatella larval density and the required precision level (Fig. 2). For example, according to Green's model (Fig. 2), at a precision level of $D=0.20$, which is close to that recommended for use in pest management programs involving larvae, MSS varied from a minimum of 3 samples when total population density was more than 3 larvae/sample to 10 samples when population density was between 1 and 2 larvae/sample. To achieve a conservative precision level of $D=0.10$, proposed for studies on population dynamics, 12 samples were needed as a minimum when the mean density of A. lineatella is more than 2 larvae/sample. Similar results were predicted by Kuno's model (Fig. 2) since in most cases MSS was only slightly higher than that predicted by Green's model.

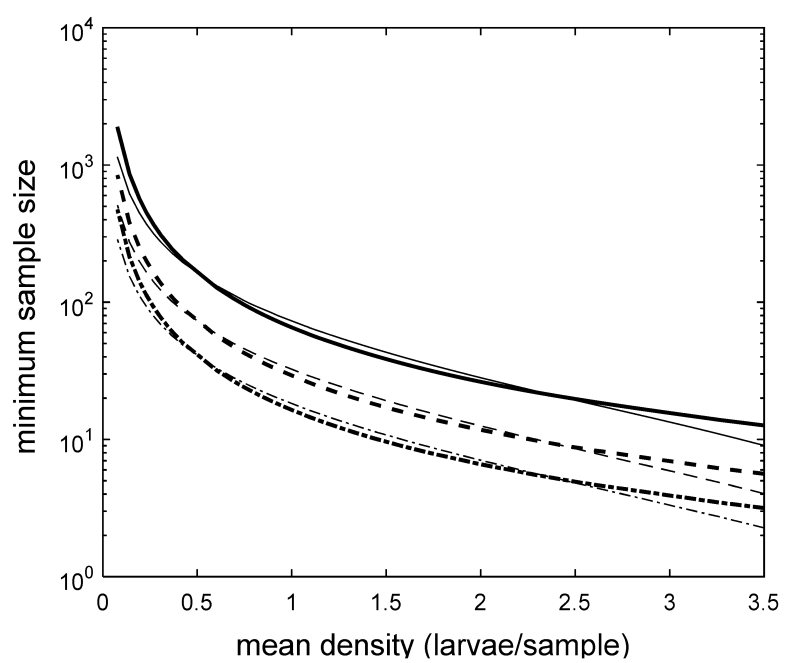

Fig. 2. Minimum sample size of larvae of $A$. lineatella required for a given fixed level of precision $D$ according to Green's (bold lines) and Kuno's models (thin lines). Precision levels: $D=0.10$ (solid lines), 0.15 (dashed lines) and 0.20 (dot-dashed lines).

\subsection{Sequential sampling}

The cumulative number of fruit damaged by larvae of A. lineatella $T_{n}$ also increased with the size of the sample (2-year old branch with fruit) and desired precision level (Fig. 3). For example, the cumulative number of fruit with larvae, according to Green's sequential plan, varied from 9 when the sample size is 1 , to 17 when the sample size is close to 45 and at the desired precision level of $D=0.20$ suggested for pest management (Fig. 3a). To achieve the higher precision level of $D=0.10$, the sample size needs to be increased from 1 to 2 for a cumulative number of fruit damaged by larvae of $A$. lineatella equal to 25 , to a sample size of 60 for a cumulative number of fruit damaged close to 50 , respectively.

Fig. $3 \mathrm{~b}$ presents the critical levels according to Kuno's fixed sampling plan generated from the parameters obtained from Iwao's regression. At the precision levels of $D=0.15$ and $D=0.20$, when the sample size is increased from 0 to 20, the cumulative number of fruit damaged by $A$. lineatella increases rapidly from 4 to 40 and remains quite constant afterwards as shown by a horizontal trend. At the precision level of $D=0.10$, which is the most conservative, the relation between optimal sample size and cumulative number of fruit with larvae shows similar tendencies for a sample size close to 10 to that predicted at the two other levels of precision, but the cumulative number of fruit with larvae increases considerably at even higher levels.

Table 1. Parameter estimates $(95 \% \mathrm{Cl}$ in parentheses) and goodness of fit measures of the three models linking mean population density of larvae of $A$. lineatella to population variance [models (1a) and (2b)] and probability of patch occupancy [model (3)], SSE: sum of square error, $R^{2}$ - R square, Adj. $R^{2}$ - adjusted R square, RMSE - root mean square error.

\begin{tabular}{|c|c|c|c|c|c|c|c|}
\hline \multirow{3}{*}{ Name } & \multicolumn{7}{|c|}{ Dispersion index models } \\
\hline & \multicolumn{2}{|c|}{ Parameter estimates } & \multicolumn{5}{|c|}{ Goodness of fit } \\
\hline & $\alpha$ & $b$ & SSE & $\mathrm{R}^{2}$ & Adj. $R^{2}$ & RMSE & $p$ \\
\hline Taylor Power law & $0.656(0.581,0.731)$ & $0.687(0.554,0.821)$ & 2.087 & 0.77 & 0.76 & 0.215 & $<0.0001$ \\
\hline Iwao patchiness regression & $-0.105(-0.232,0.021)$ & $0.835(0.751,0.919)$ & 3.114 & 0.89 & 0.89 & 0.263 & $<0.0001$ \\
\hline Nachman & $0.716(0.654,0.777)$ & $-0.676(-0.796,-0.556)$ & 0.264 & 0.82 & 0.82 & 0.076 & $<0.0001$ \\
\hline
\end{tabular}



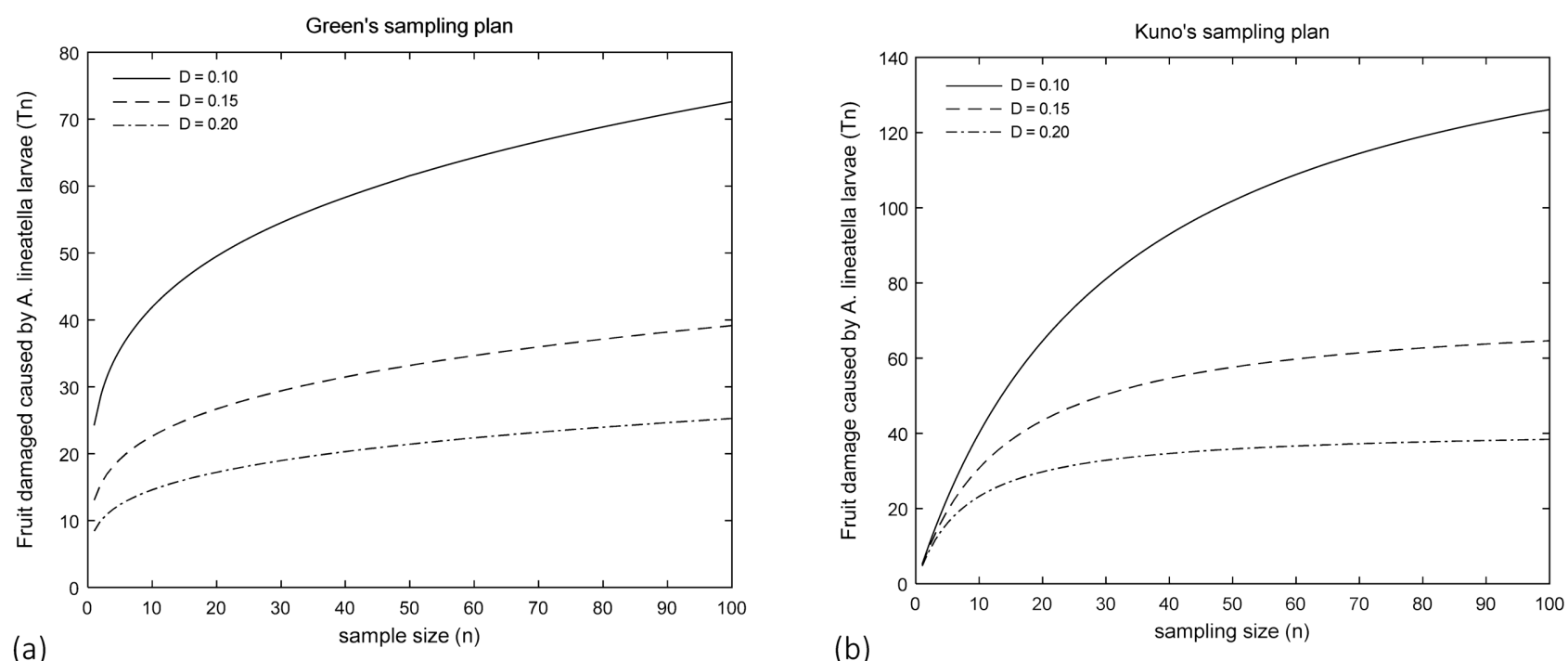

(a)

Fig. 3. Sequential sampling stop lines for fixed precision levels (D) used to estimate the density of $A$. lineatella obtained using (a) Green's and (b) Kuno's models. Precision levels: $D=0.10$ (solid lines), 0.15 (dashed lines) and 0.20 (dot-dashed lines) as in Fig. 2.

\subsection{Validation of sampling plans}

Resampling analysis for the prefixed levels of precision $D=0.10,0.15$ and 0.20 are shown in Fig. 4. The summarized outputs show the size of the sample as a function of the mean density of fruit with $A$. lineatella larvae and include the mean, as well as the maximum and minimum values for a certain precision. The means are estimated after resampling 500 times with replacement using all the sample sizes used for validation and all population densities. According to the results, the mean precision value (represented by square symbols) is closer to the desired level, but the extreme values of precision (shown as dashed lines) can be higher or lower between any one of the sample points. As expected, the sample size decreased quickly with mean density of fruit with $A$. lineatella larvae/sample at each precision level. However, variability among samples decreased with mean density. In addition, a larger sample is required for computing the mean density at a higher precision. In all cases, both Green's and Kuno's plan generated similar levels of precision (Table 2). The actual mean precision was in most cases close to that specified in the sample plan, and the extreme values were reasonable.

\section{DISCUSSION}

Identifying what type of spatial distribution a pest of fruit has is important for developing appropriate plans for sampling for IPM. Variance-to-mean relations provide fundamental information about the spatial distribution of a species and are further used as parameters in models that indicate statistically valid plans for sampling, which provide efficient means of assessing whether economic levels of insect pests are present (Pedigo \& Buntin, 1994).

In particular Taylor and lwao relationships are extremely useful because they indicate that the variances for estimated means and their parameters are density-invariant, i.e. they are characterized by arithmetic stability over time and space (Pedigo \& Buntin, 1994). However, there are cases where the index, $b$, may not be consistent from site to site across a continent, or it may depend on pesticide use (Trumple et al., 1989; Pedigo \& Buntin, 1994). Nevertheless, the parameters of these models provide fundamental information on the spatial distributions of pests and are critically important for the development of sampling procedures (Teylor et al., 1988; Pedigo \& Buntin, 1994).

This study of the spatial distribution of peaches damaged by $A$. lineatella in the field using density-invariant dispersion indices provides, for the first time, a cost-effective method of sampling that could be added by plant protection authorities and peach growers to existing IPM programs. Currently, there are no plans for sampling available to plant protection advisors and growers for estimating the damage done to peaches by A. lineatella and management actions are often based on preventive measures such as spraying based on shoot flagging and/or numbers of first generation moths captured.

Table 2. Summary of the performance for Green's and Kuno's plans for sequential sampling based on the RVSP procedure.

\begin{tabular}{|c|c|c|c|c|c|c|c|c|c|c|}
\hline \multirow{2}{*}{$\begin{array}{l}\text { Sampling } \\
\text { Plan }\end{array}$} & \multirow{2}{*}{$\begin{array}{c}\text { Desired } \\
\text { precision }\end{array}$} & \multicolumn{3}{|c|}{ Precision over 500 simulations } & \multicolumn{3}{|c|}{ Sample size } & \multicolumn{3}{|c|}{ Range of larval densities } \\
\hline & & Mean & Min & Max & Mean & Min & Max & Mean & Min & Max \\
\hline \multirow{3}{*}{ Green's } & 0.10 & 0.14 & 0.08 & 0.18 & 117.62 & 44.00 & 449.00 & 0.83 & 0.23 & 1.06 \\
\hline & 0.15 & 0.21 & 0.12 & 0.26 & 53.37 & 20.00 & 202.00 & 0.86 & 0.23 & 1.14 \\
\hline & 0.20 & 0.27 & 0.17 & 0.34 & 30.68 & 17.00 & 115.00 & 0.89 & 0.23 & 1.48 \\
\hline \multirow{3}{*}{ Kuno's } & 0.10 & 0.13 & 0.09 & 0.172 & 118.00 & 49.00 & 375.00 & 0.82 & 0.63 & 1.41 \\
\hline & 0.15 & 0.20 & 0.14 & 0.30 & 52.87 & 30.00 & 166.00 & 0.80 & 0.23 & 1.38 \\
\hline & 0.20 & 0.27 & 0.18 & 0.32 & 30.56 & 13.00 & 97.00 & 0.88 & 0.23 & 1.19 \\
\hline
\end{tabular}



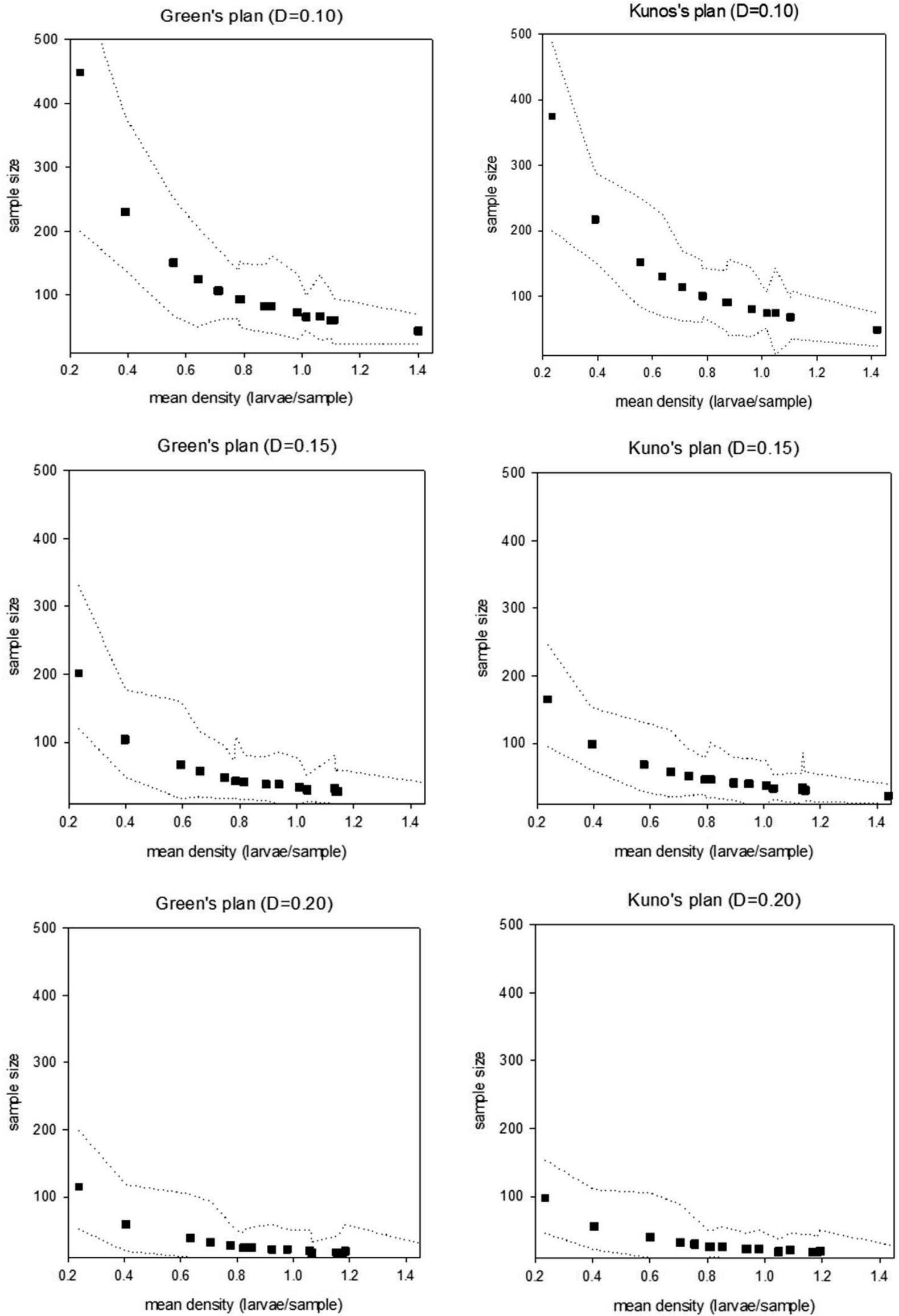

Fig. 4. Validation of Green's (left column) and Kuno's (right column) plans for sequential sampling using independent field data on peach fruit damage caused by larvae of $A$. lineatella. Symbols denote mean values; extreme values for each simulated data set marked by dotted lines. Precision levels: $\mathrm{D}=0.10$ (top row), 0.15 (middle row) and 0.20 (bottom row). 


\subsection{Variance to mean dispersion indices}

All three commonly used variance-to-mean relationships fit the data well. However, the overall performance of Iwao's model was slightly better than that of Nachman and Taylor's regression models. The results indicate a uniform or close to random, rather than aggregated, larval distribution. This agrees with previous geostatistical studies that show very low spatial autocorrelations (Damos, 2017). The uniform or random spatial distribution of damaged fruit may be explained by a uniform spatial arrangement of orchards and samples of fruit, and females may have the same probability of finding suitable oviposition space in experimental orchards, although the role of other factors should not be excluded (Damos, 2017).

\subsection{Plans for fixed precision sequential sampling}

Critical thresholds are determined by the value of the aggregation parameter $b$ in Taylor's regression model. A. lineatella larvae were found to be uniformly distributed $(b<$ 1) rather than aggregated $(b>1)$ as in other species. Critical thresholds for the optimal sample size based on Kuno's sampling plan indicated a small number of sampling units can estimate the mean population density of $A$. lineatella larvae with a precision of $20 \%$. Moreover, those based on Green's and Kuno's models indicated that, as sample size increases from 0 to 20 , the cumulative number of larvae also increases towards an asymptote. This is the opposite of what generally occurs (e.g., Lee et al., 2005; Cocco et al., 2015), but the results are in agreement with those for another species of Gelechiidae, Phthorimaea operculella (Shabi \& Rajabpour, 2017). Green's and Kuno's methods generated very similar mean sample sizes for all three chosen levels of sampling precision although a slight advantage of Green's sequential plan for field application may be related to the smaller sample size needed to achieve the threshold.

\subsection{Validation of sequential sampling plans}

The validation of the sampling plan protocol following Naranjo \& Hutchison (1997) showed that sequential sampling plans can be fairly reliable even though the independent dataset used for validation was relatively small. Similar fixed precision sequential sampling plans have been established and evaluated for other insect species, including different stages of whiteflies infesting sweet potato and cotton (Naranjo \& Flint, 1995), larvae of Heliothis zea and Ostrinia nubilalis on corn (O'Rourke \& Hutchison, 2003), eggs of Colias lesbia on alfalfa (Serra et al., 2013) and active stages of Harmonia axyridis on sweet corn (Koch et al., 2006).

\subsection{Concluding remarks}

The suggested plans for sampling may be considered for use in peach orchards as it provides plant protection advisors and researchers with a proper decision tool for quantifying the spatial distribution of the peach twig borer. But a wider implementation of the currently proposed plans for sampling requires further research on $A$. lineatella host preference as well as inter and intraspecies competition and how it may affect its spatial distribution. Moreover, the current plans were developed and validated with a limited dataset and should thus be validated with new data and implemented over broader ranges and in new areas with different agronomic and environmental characteristics. Nevertheless, both the sampling plans presented may have utility per se as they performed equally well and provided a basic mean for implementing pest management programs that will facilitate the estimating of the density of larvae of A. lineatella and decision-making.

In conclusion, the current work provides fixed sampling plans that can be used to balance the cost of sampling programs for monitoring the damage of $A$. lineatella with the benefit of reducing infestations and increasing profits. Considering that $A$. lineatella is the most important pest in peach growing areas, improved knowledge of its spatial distribution on trees coupled with the plans for sequential sampling provides a foundation for more selective and efficient pest management.

ACKNOWLEDGEMENTS. The author would like to thank two anonymous reviewers for their valuable comments and the associate editor D. Boukal for his suggestions, which have greatly improved the contents of this MS.

\section{REFERENCES}

BALACHOWSKY A.S. 1966: Entomologie appliquée à l'agriculture. Traité. Tome II. Lépidoptères. Masson et Cie éditeurs, Paris, $1057 \mathrm{pp}$.

Binns M.R 1994: Sequential sampling for classifying pest status. In Pedigo L.P. \& Buntin G.D. (eds): Handbook of Sampling Methods for Arthropods in Agriculture. CRC Press, Boca Raton, pp. 137-174.

BinNs M.R. \& NyROP J.P. 1992: Sampling insect populations for the purpose of IPM decision making. - Annu. Rev. Entomol. 37: 427-453.

Bisseleua D.H.B., Yede \& Vidal S. 2011: Dispersion models and sampling of cacao mirid bug Sahlbergella singularis (Haglung) (Hemiptera: Miridae) on Theobroma cacao L. in southern Cameroon. - Environ. Entomol. 40: 111-119.

Cocco A., Serra G., Lentini A., Deliperi S. \& Gavino D. 2015: Spatial distribution and sequential sampling plans for Tuta absoluta (Lepidoptera: Gelechiidae) in greenhouse tomato crops. - Pest Manag. Sci. 71: 1311-1323.

Damos P. 2017: Geostatistical characterization of fruit damage caused by Anarsia lineatella (Lepidoptera: Gelechiidae) in organic fruit orchards and implications for its management. Int. J. Pest Manag. 63: 1-9.

Damos P. \& Savopoulou-Soultani M. 2010: Population dynamics of Anarsia lineatella in relation to crop damage and the development of economic injury levels. - J. Appl. Entomol. 134: 105-115.

Draper N. \& Sмith H. 1998: Applied Regression Analysis. John Wiley \& Sons, New York, 736 pp.

Еквом B.S. 1987: Incidence counts for estimating densities of Rhopalosiphum padi (Homoptera: Aphididae). — J. Econ. Entomol. 80: 933-935.

EPPO Global Database 2017: European and Mediterranean Plant Protection Organization. URL: https://gd.eppo.int/ (last accessed 1 Apr. 2017).

GREEN R.H. 1970: On fixed precision sequential sampling. Res. Popul. Ecol. 12: 249-251. 
Hahn N.G., Rodriguez-SaOna C. \& Hamilton G.C. 2017: Characterizing the spatial distribution of brown marmorated sting bug, Halyomorpha halys Stål (Hemiptera: Pentatomidae), populations in peach orchards. - PLoS ONE 12(3): e170889, $20 \mathrm{pp}$.

He F. \& Gaston K.J. 2000: Estimating species abundance from occurrence. - Am. Nat. 156: 553-559.

Hepworth G. \& McFarlane J.R. 1992: Systematic presenceabsence sampling method applied to twospotted spider mite (Acari: Tetranychidae) on strawberries in Victoria, Australia. - J. Econ. Entomol. 85: 2234-2239.

Hutchison W.D. 1994: Sequential sampling to determine population density. In Pedigo L. \& Buntin G. (eds): Handbook of Sampling Methods for Arthropods in Agriculture. CRC Press, Boca Raton, pp. 207-244.

Ifoulis A.A. \& Savopoulou-Soultani M. 2006: Developing optimum sample size and multistage sampling plans for Lobesia botrana (Lepidoptera: Tortricidae) larval infestation and injury in northern Greece. - J. Econ. Entomol. 99: 1890-1898.

Iwao S. 1968: A new regression method for analysing the aggregation pattern of animal populations. - Res. Popul. Ecol. 10: $1-20$.

IWAo S. 1975: A new method of sequential sampling to classify populations relative to a critical density. - Res. Popul. Ecol. 16: $281-288$.

JøRGENSEN B. 1997: The Theory of Exponential Dispersion Models. Chapman and Hall, London, $237 \mathrm{pp}$.

Koch R., Burkness E. \& Hutchinson W. 2006: Spatial distribution and fixed-precision sampling plans for the ladybird Harmonia axyridis in sweet corn. - BioControl 51: 741-751.

Kuno E. 1969: A new method of sequential sampling to obtain the population estimates with a fixed level of precision. - Res. Popul. Ecol. 11: 127-136.

Kuno E. 1991: Sampling and analysis of insect populations. Annu. Rev. Entomol. 36: 285-304.

Lee D.H., Park J.J., Park H. \& Cho K. 2005: Estimation of leafmine density of Liriomyza trifolii (Diptera: Agromyzidae) in cherry tomato greenhouses using fixed precision sequential sampling plans. - J. Asia Pac. Entomol. 8: 81-86.

Lloyd M. 1967: Mean crowding. - J. Anim. Ecol. 36: 1-30.

Mace A.E. 1974: Sample Size Determination. R.E. Krieger, Huntington, NY.

NACHMAN G. 1981: A mathematical model of the functional relationship between density and the spatial distribution of a population. - J. Anim. Ecol. 50: 453-460.

NACHMAN G. 1984: Estimates of mean population density and spatial distribution of Tetranychus urticae (Acarina: Tetranychidae) and Phytoseiulus persimilis (Acarina: Phytoseidae) based upon the proportion of empty sampling units. - J. Appl. Ecol. 21: 903-913.

NARANJo S.E. \& Fuint H.M. 1995: Spatial distribution of adult Bemisia tabaci in cotton and development and validation of fixedprecision sequential sampling plans for estimating population density. - Environ. Entomol. 24: 261-270.

NARANJo S.E. \& Hutchinson W.D. 1997: Validation of arthropod sampling plans using a resampling approach: software and analysis. - Am. Entomol. 43: 48-57.

NARANJo S.E. \& Hutchinson W.D. 2016: Resampling Validation of Sampling Plans (RVSP) V. 2. URL: https://www.ars.usda. gov/research/software/download/?softwareid=129 (last accessed 1 Apr. 2017).

Nyrop J.P. \& Binns M. 1991: Quantitative methods for designing and analyzing sampling programs for use in pest management. In Pimentel D. (ed.): Handbook of Pest Management in Agriculture, Vol. 2. CRC Press, Boca Raton, pp. 67-132.

Nyrop J.P., Agnello A.M., Kovach J. \& Reissig W.H. 1989: Binomial sequential classification sampling plans for European red mite (Acari: Tetranychidae) with special reference to performance criteria. - J. Econ. Entomol. 82: 482-490.

O'Rourke P.K. \& Hutchinson W.D. 2003: Sequential sampling plans for estimating European corn borer (Lepidoptera: Crambidae) and corn earworm (Lepidoptera: Noctuidae) larval density in sweet corn ears. - Crop. Prot. 22: 903-909.

Pedigo L.P. \& Buntin G.D. 1994: Handbook of Sampling Methods for Arthropods in Agriculture. CRC Press, Boca Raton, FL, $336 \mathrm{pp}$.

Perry R.L. 1973: Skip-lot sampling plans. - J. Qual. Technol. 5: $123-130$

Serra G.V., La Porta N.C., Avalos S. \& Mazzuferi V. 2013: Fixed-precision sequential sampling plans for estimating alfalfa caterpillar, Colias lesbia, egg density in alfalfa, Medicago sativa, fields in Córdoba, Argentina. - J. Insect Sci. 13: 41, $9 \mathrm{pp}$.

Shabi M. \& Rajabpour A. 2017: A fixed-precision sequential sampling plan for the potato tuberworm moth, Phthorimaea operculella Zeller (Lepidoptera: Gelechiidae), on potato cultivars. - Neotrop. Entomol. 46: 388-395.

Sorenson C.J. \& GunNell F.H. 1955: Biology and control of the Peach Twig Borer (Anarsia lineatella Zeller) in Utah. - Utah Agric. Exp. Stn. Bulletin No. 379 (paper 343), 19 pp. URL: https://digitalcommons.usu.edu/uaes bulletins/343.

Southwood T.R.E. 1978: Ecological Methods, with Particular Reference to the Study of Insect Populations. 2nd ed. John Wiley and Sons, New York, $524 \mathrm{pp}$.

TAYLOR L.R. 1961: Aggregation, variance and the mean. - Nature 189: 732-735.

TAYLOR L.R. 1984: Assessing and interpreting the spatial distributions of insect populations. - Annu. Rev. Entomol. 29: 321-357.

TAYlor L.R., Woiwod I.P. \& Perry J.N. 1978: The density-dependence of spatial behaviour and the rarity of randomness. - J. Anim. Ecol. 37: 383-406.

TAYlor L.R., Perry J.N., Woiwod I.P. \& TAYlor R.A.J 1998: Specificity of the power-law exponent in ecology and agriculture. - Nature 332: 721-722.

Trumple T., Brewer M.J., Shelton A.M. \& Nyrop J.P. 1989: Transportability of fixed precision level sampling plans. Res. Popul. Ecol. 31: 325-342.

Tscharntke T., Dewenter S., Kruess A. \& Thies C. 2002: Characteristics of insect populations on habitat fragments: a mini review. - Ecol. Res. 17: 229-239.

Vinatier F., Tixier P., Duyck P.F. \& Lescourret F. 2011: Factors and mechanisms explaining spatial heterogeneity: a review of methods for insect populations. - Meth. Ecol. Evol. 2: 11-12.

Young L.J. \& Young J.H. 1998: Statistical Ecology. Kluwer Academic Publishers, Dordrecht, 565 pp.

Received February 26, 2018; revised and accepted October 10, 2018 Published online November 14, 2018 